\title{
MiR137 is an androgen regulated repressor of an extended network of transcriptional coregulators
}

\author{
Emeli M. Nilsson ${ }^{1, *}$, Kristian B. Laursen ${ }^{2, *}$, Jonathan Whitchurch ${ }^{1,3}$, Andrew \\ McWilliam ${ }^{1}$, Niels $\varnothing$ dum $^{4}$, Jenny L. Persson ${ }^{5}$, David M. Heery ${ }^{3}$, Lorraine J. Gudas ${ }^{2}$ \\ and Nigel P. Mongan ${ }^{1,2}$ \\ ${ }^{1}$ Faculty of Medicine and Health Sciences, School of Veterinary Medicine and Science, University of Nottingham, United \\ Kingdom \\ 2 Department of Pharmacology, Weill Cornell Medical College, New York, NY, USA \\ ${ }^{3}$ School of Pharmacy, University of Nottingham, United Kingdom \\ ${ }^{4}$ Department of Immunology and Microbiology, University of Copenhagen, Copenhagen, Denmark \\ ${ }^{5}$ Clinical Research Center, Lund University, Malmö, Sweden \\ * These authors have contributed equally to this work \\ Correspondence to: Nigel P. Mongan, email: Nigel.Mongan@nottingham.ac.uk \\ Keywords: epigenetic, prostate, nuclear receptor, metastases, Gleason \\ Received: August 05, $2015 \quad$ Accepted: September 12, $2015 \quad$ Published: October 05, 2015
}

This is an open-access article distributed under the terms of the Creative Commons Attribution License, which permits unrestricted use, distribution, and reproduction in any medium, provided the original author and source are credited.

\section{ABSTRACT}

Androgens and the androgen receptor (AR) play crucial roles in male development and the pathogenesis and progression of prostate cancer (PCa). The AR functions as a ligand dependent transcription factor which recruits multiple enzymatically distinct epigenetic coregulators to facilitate transcriptional regulation in response to androgens. Over-expression of AR coregulators is implicated in cancer. We have shown that over-expression of KDM1A, an AR coregulator, contributes to PCa recurrence by promoting VEGFA expression. However the mechanism(s) whereby AR coregulators are increased in PCa remain poorly understood. In this study we show that the microRNA hsa-miR-137 (miR137) tumor suppressor regulates expression of an extended network of transcriptional coregulators including $K D M 1 A / L S D 1 / A O F 1$, KDM2A/JHDM1A/FBXL11, KDM4A/JMJD2A, KDM5B JARID1B/PLU1, KDM7A/JHDM1D/ PHF8, MED1/TRAP220/DRIP205 and NCOA2/SRC2/TIF2. We show that expression of miR137 is increased by androgen in LnCaP androgen PCa responsive cells and that the miR137 locus is epigenetically silenced in androgen LnCaP:C4-2 and PC3 independent PCa cells. In addition, we found that restoration of miR137 expression down-regulates expression of VEGFA, an AR target gene, which suggests a role of miR137 loss also in cancer angiogenesis. Finally we show functional inhibition of miR137 function enhanced androgen induction of PSA/KLK3 expression. Our data indicate that miR137 functions as an androgen regulated suppressor of androgen signaling by modulating expression of an extended network of transcriptional coregulators. Therefore, we propose that epigenetic silencing of $\operatorname{miR} 137$ is an important event in promoting androgen signaling during prostate carcinogenesis and progression.

\section{INTRODUCTION}

Epigenetic silencing of tumor suppressor microRNAs (miRs) has recently emerged as an important mechanism of carcinogenesis [1]. MiRs are endogenous mediators of RNA silencing which function to attenuate transcriptional and translational outputs [2]. Each miR can functionally interfere with multiple target mRNAs in vivo, and thus a single miR has the potential to down-regulate an extended network of transcriptional targets. Conversely, 
the epigenetic loss of a specific miR would permit increased expression of multiple target genes. Numerous examples of such tumor suppressor miRs have been described [reviewed in 1, 3]. Epigenetic silencing of $h s a$ $m i R-137$ ( $m i R 137)$ has recently emerged as an important event in neuroblastoma [4], glioblastoma [5], colorectal $[6,7]$, breast [8], head and neck [9, 10] and bladder [11] cancers. Known, validated targets for $m i R 137$ include the cell cycle regulator $C d c 42$ [7], estrogen related receptor $E R R \alpha / N R 3 B 1$ [12], p160 nuclear receptor coactivators [13] and the lysine specific demethylase 1 (KDM1A, $L S D 1$ ), a transcriptional coregulator [6] which is overexpressed in many cancers [14 and references therein]. Loss of miR137 expression is associated with increased cell proliferation and invasion, consistent with a role in metastatic disease [6].

KDM1A plays important roles in androgen receptor (AR) signaling $[15,16]$ and is over-expressed in recurrent prostate cancer $(\mathrm{PCa})[14,17]$. The AR is a member of the ligand dependent transcription factor superfamily of nuclear receptors and mediates the transcriptional actions of the androgens, testosterone, and dihydrotestosterone. The AR itself plays an essential role both in male development [18] and prostate [19] and other cancers [20]. Nuclear receptors, including the AR, recruit multiple enzymatically diverse transcriptional coregulators in response to agonist activation [21 and references therein]. These transcriptional coregulators are essential mediators of the epigenetic regulation of transcription by modulating histone modifications, including lysine methylation and acetylation [reviewed in 22, 23]. These coregulators mediate the transcriptional activities of other nuclear receptors, most notably the estrogen receptors [24] and other transcription factors [23]. Aberrant expression and function of transcriptional coregulators are implicated in numerous human malignancies, including PCa $[14,23$, 25-29].

We [14] and others [15-17] have reported that expression of KDM1A is increased in $\mathrm{PCa}$ and is associated with poorer outcomes. We have also shown that $K D M 1 A$ contributes to poorer prostate outcomes by promoting pro-androgenic and pro-angiogenic pathways [14]. However understanding of the mechanism(s) contributing to increased expression of $K D M 1 A$ and other coregulators [30] in PCa remains incomplete. In this report we first sought to determine whether specific microRNAs, including miR137, which are expressed in normal prostate cells but lost in $\mathrm{PCa}$ cells, function as repressors of $K D M 1 A$. Our analysis revealed that miR137 targets an extended network of transcriptional coregulators, including $K D M 1 A / L S D 1 / A O F 1, K D M 2 A / J H D M 1 A /$ FBXL11, KDM4A/JMJD2A, KDM5B/JARID1B/PLU1, KDM7A/JHDM1D/PHF8, MED1/TRAP220/DRIP205 and $N C O A 2 / S R C 2 / T I F 2$. Ectopic restoration of $m i R 137$ expression decreases expression of these transcriptional coregulators. We show that restoration of $m i R 137$ function is associated with a decrease in VEGFA expression which we have previously shown to be positively regulated by the AR-KDM1A complex [14]. We show that expression of $m i R 137$ is increased by androgen in androgen-responsive cells. Finally, we show that functional inhibition of miR137 enhances androgen signaling. Our data indicates that the epigenetic status of the miR137 locus influences expression of an extended network of transcriptional coregulators and that miR137 functions as an androgen regulated suppressor of epigenetic coregulators. We therefore propose that epigenetic silencing of $m i R 137$ is an important event in promoting androgen signaling during prostate carcinogenesis and progression.

\section{RESULTS}

\section{Expression of $m i R 137$ is epigenetically silenced by DNA methylation in prostate cancer cells}

Expression of $K D M 1 A$ is increased in many solid tumors and leukemias [14 and references therein]. However the mechanisms whereby KDM1A expression is increased remain poorly understood. One potential mechanism relates to the loss of a repressor microRNA [31]. We therefore used the PicTar [32], Targetscan [33], miRDB [34] and miRanda [35] microRNA target prediction tools and identified miR137 as a potential regulator of $K D M 1 A$ (Figure 1A, Supplemental Table 1). $M i R 137$ was also recently shown to regulate $K D M 1 A$ in colon cancer [6] and neuroblastoma [4]. MicroRNAs are known to regulate expression of multiple targets which are often functionally related. For this reason we next examined whether miR137 also regulated expression of genes functionally related to $K D M 1 A$. Our analysis identified $K D M 2 A$, KDM4A, KDM5B, KDM7A, MED1, $C B P$, and $S U Z 12$ as potential miR137 targets in PCa. By real time qPCR we detected abundant expression of miR137 in normal prostate epithelial cells (PREC), but reduced $m i R 137$ expression in $\mathrm{LnCaP}$ (representative of localized $\mathrm{PCa}$ ) and absent miR137 expression in LnCaP:C4-2 (a bone metastatic derivative of the parental LnCaP cell line) and PC3 (representative of aggressive androgen independent metastatic PCa) (Figure 1B). We next used bisulfite sequencing PCR (BSP) to determine the DNA methylation status of miR137 locus in PREC and LNCaP. We confirmed these findings by completing methylation specific PCR (MSP) in PREC, LnCaP, LnCaP:C4-2 and PC3 cells. MSP and BSP indicate extensive methylation of the miR137 locus in PCa cell lines (Figure 1C, 1D). We next assessed the DNA methylation status of the miR137 locus in publically available patient genomic datasets [36] and the cancer genome atlas prostate adenocarcinoma (PRAD) DNA methylation dataset. The miR137 locus harbors significantly higher 


\section{A}

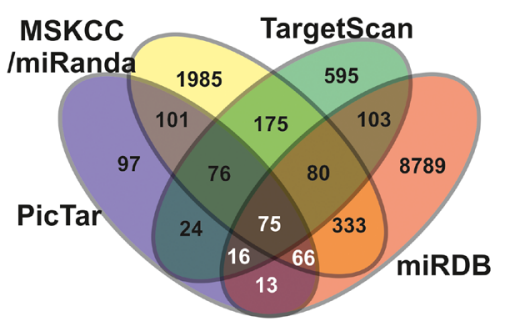

B

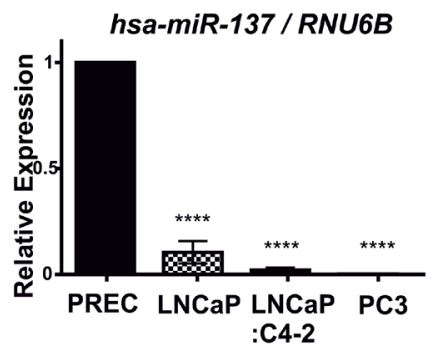

C

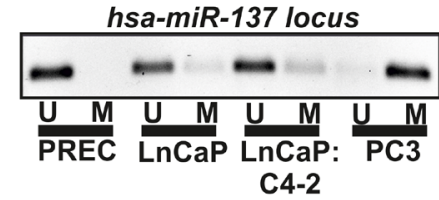

$M=$ methylated $\mathrm{U}=$ unmethylated
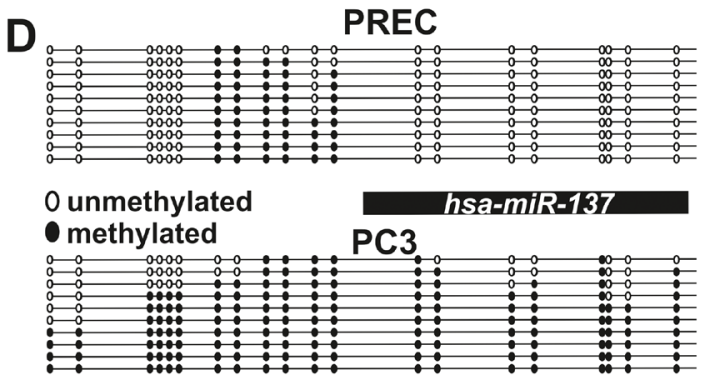

TCGA PRAD DNA methylation $(\mathrm{n}=549)$

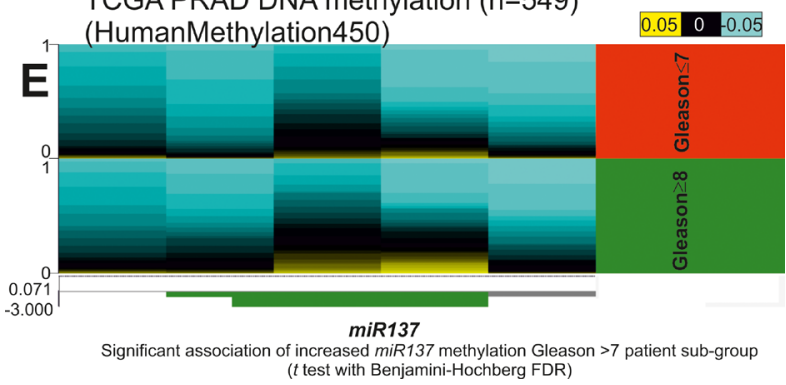

Figure 1: A. Venn diagram of putative miR137 target genes identified by four different tools. B. Quantitative RTPCR was used to measure miR137 expression in prostate cells. Normal prostate epithelial cells (PREC) exhibited the most abundant miR137 expression as compared to LnCaP, LnCaP:C4-2 and PC3 PCa cells. C. Genomic DNA was isolated from prostate epithelial cells (PREC) and PCa cell lines, $\mathrm{LNCaP}$, LNCaP:C4-2 and PC3 cells and subjected to bisulfite modification. The location of the miR137 transcript relative to the CpGs analyzed is indicated. Methylation specific PCR was used to assess methylation a crucial CpG island. The miR137 locus was unmethylated in normal PREC, but hemi-methylated in LNCaP and LNCaP:C4-2 cells. The miR137 locus in PC3 was methylated. D. BSP primers were used to amplify the entire CpG island of the miR137 locus in PREC and PC3 cells. The miR137 locus was unmethylated in normal PREC, but densely methylated in PC3 PCa cells. Black circles indicate methylated CpGs, whereas white circles indicate unmethylated CpGs. The data represent a minimum of 10 independent alleles from each respective cell line. Consistent with the literature, methylation of the miR137 locus in PCa cells correlates with lower miR137 expression as compared with the unmethylated miR137 locus in normal PREC. E. We used the cancer genome atlas prostate adenocarcinoma (PRAD) dataset DNA methylation dataset to correlate methylation of the miR137 locus and Gleason grade. Increased DNA methylation (indicated in yellow) at the cg05423529, cg14783814 and cg22333214 locations in the $m i R 137$ locus is significantly associated ( $t$ test with Benjamini-Hochberg FDR) with Gleason grades $\geq 8$ patient sub-group (indicated in green, N-196) as compared to patients with Gleason grades $\leq 7$ (indicated in red, $n=323$ ). 
methylation in tumor tissue as compared to non-malignant tissue in a variety of human cancer types, including PCa (Supplemental Figure 1). Indeed increased miR137 methylation correlates with increasing $\mathrm{PCa}$ Gleason grade (Figure 1E). We have shown that expression of miR137 was significantly lower in all PCa cells relative to normal prostate epithelial cells (Figure 1B). Consistent with this, our analysis of a published PCa patient transcriptomic cohort, shows that median miR137 expression is lower in PCa patients who experience PCa recurrence (Supplemental Figure 2A), indicating epigenetic loss of miR137 expression is associated with PCa recurrence [37].

\section{An extended network of transcriptional} coregulators are novel $m i R 137$ targets in vitro

Novel putative miR137 targets were prioritized for experimental validation if they were identified by a minimum of two tools, had a transcription coregulatorrelated function, and were expressed in PCa cells (Supplemental Table 1). To this end we examined mRNA expression of the putative $m i R 137$ targets identified here, $K D M 1 A, K D M 2 A, K D M 2 A, K D M 5 B, K D M 7 A, C B P$, $S U Z 12, M E D 1$, and $N C O A 2$ in normal and malignant PCa cells (Figure 2A-2I). Interestingly, the expression of all putative miR137 targets tested was similar or elevated in $A R$ expressing $\mathrm{LnCaP}$ and $\mathrm{LnCaP}: \mathrm{C} 4-2 \mathrm{PCa}$ cells as compared to normal prostate epithelial cells. Having confirmed the expression of these genes in $\mathrm{PCa}$ cells, we next determined the effects of ectopic overexpression of $m i R 137$ on the mRNA and protein levels of KDM1A, KDM2A, KDM2A, KDM5B, KDM7A, CBP, SUZ12, MED1 and NCoA2. We over-expressed miR137 and scrambled control non-targeting miRNA in PC3 cells which lack endogenous miR137 but which express the validated $m i R 137$ target $K D M 1 A$ (Figure 2A). Expression of NCOA2 and KDM1A was reduced following miR137
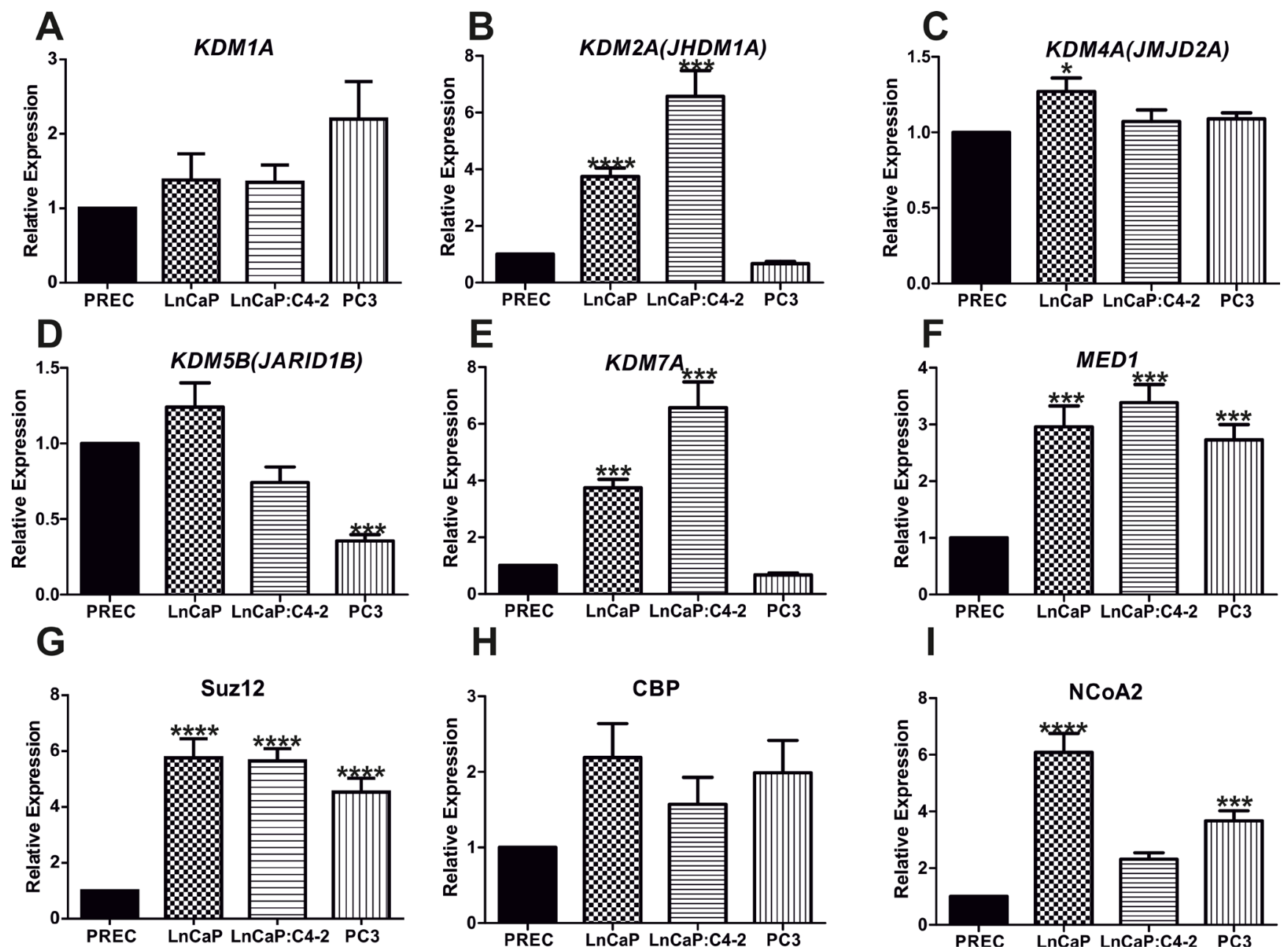

Figure 2: Identification and validation of $\mathbf{m i R} 137$ target genes. Quantitative reverse transcriptase PCR was used to compare mRNA expression of putative miR137 targets in non-malignant prostate epithelial cells (PREC), androgen responsive (LNCaP) and (LNCaP:C4-2 and PC3) hormone refractory PCa cells. Bars $=$ mean \pm SEM. $*=p<0.05 ; * * p<0.005, * * *=p<0.001, * * * *=p<0.0001$ by ANOVA with Bonferroni's post hoc test for multiple comparisons. Expression of all putative targets examined was similar or significantly higher in LnCaP and LnCAP:C4-2 PCa cell lines as compared to non-malignant PREC. Bars represent mean \pm SEM of biological triplicate experiments. 
over-expression (Figure 3B, 3C). Quantitative RTPCR and western blot analyses indicated that expression levels of NCoA2, KDM2A, KDM4A, KDM5B, KDM7A and MED1 mRNA and protein (Figure 2) were decreased following over-expression of $m i R 137$. Expression of $C B P$ transcript levels was unaffected by miR137 (Figure 3I). Although the decrease in SUZ12 did not reach statistical significance
(Figure 3J), interestingly SUZ12 protein levels were decreased by miR137 expression (Figure 3K). Previous studies have indicated NCOA2 is regulated by miR137 in other cancer types $[13,38]$. Therefore we included NCOA2 both as a positive control in our studies and to confirm that this regulation is conserved in prostate cancer. GAPDH was used as a loading control.
A
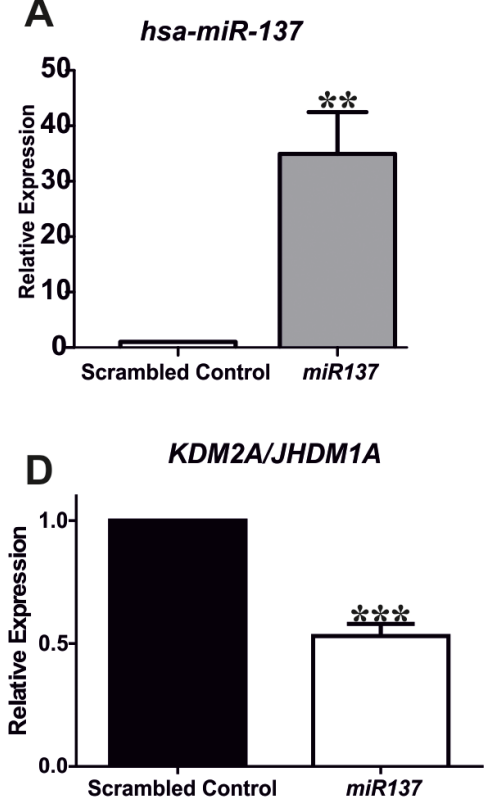

KDM7A/JHDM1D

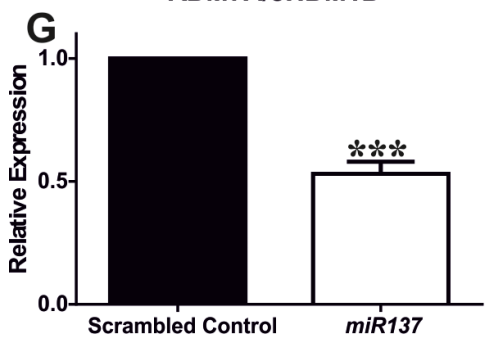

|

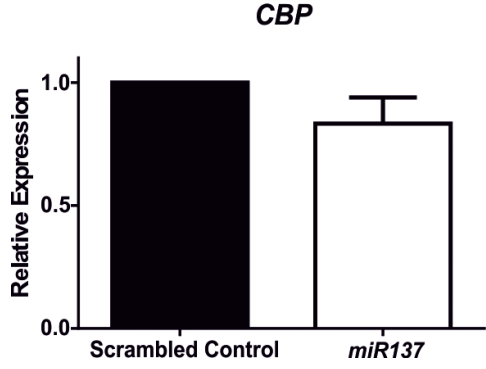

B

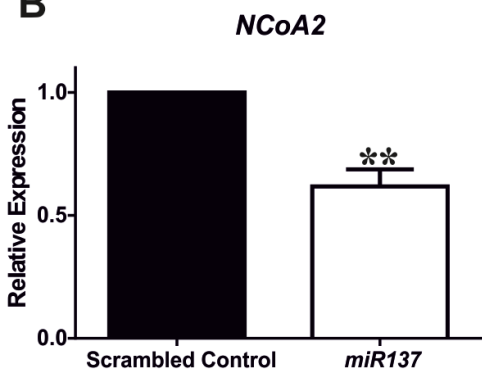

E

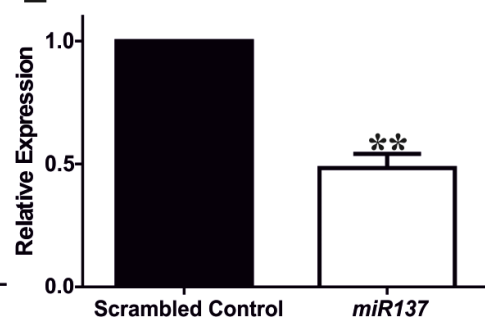

MED1

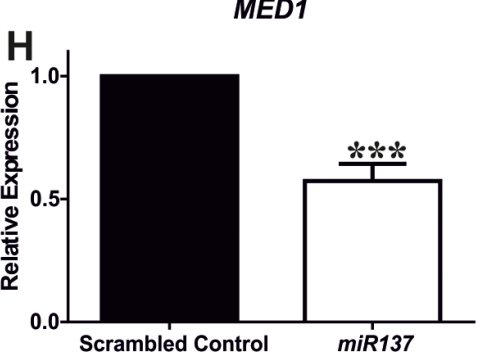

J

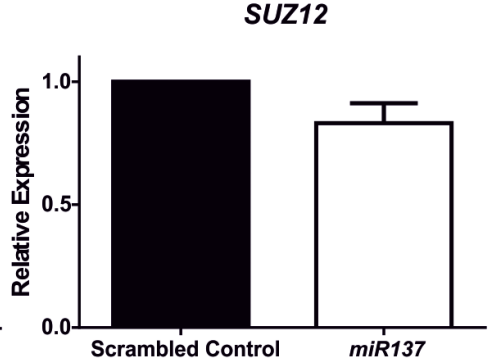

C KDM1A/LSD1

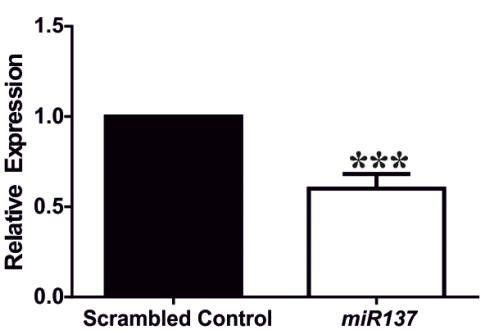

$\mathbf{F}$
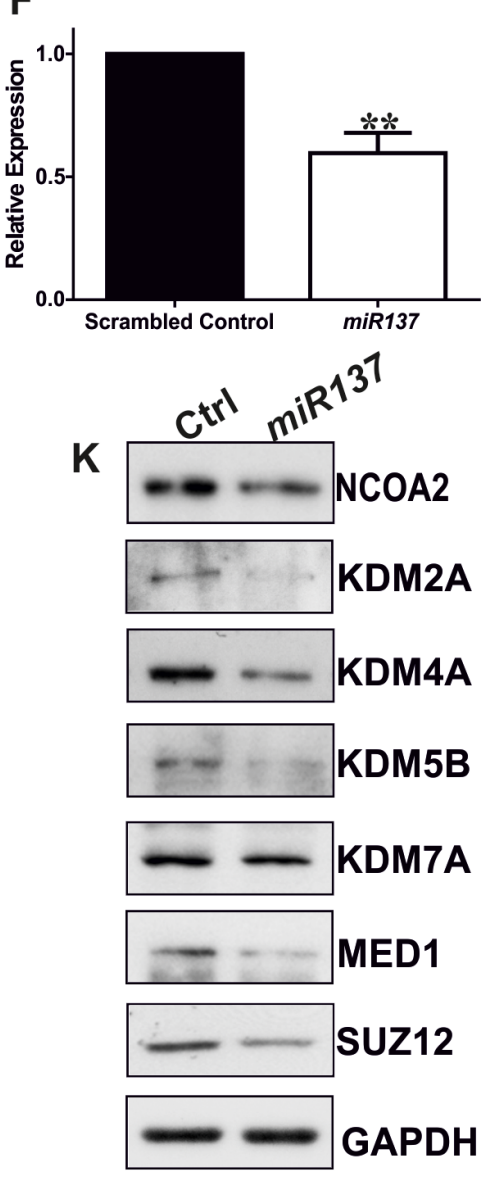

Figure 3: Quantitative RTPCR indicates ectopic over-expression of miR137 in PC3 cells induces decreases in mRNA levels of NCoA2/SRC2, KDM1A/LDS1, KDM2A, KDM4A, KDM5B, KDM7A, and MED1 A.-H. although the expression of CBP and SUZ12 was not significantly reduced I.-J. Bars represent mean \pm SEM of triplicate experiments conducted on at least two independent occasions. ${ }^{*}=p<0.05 ; * *<0.005,{ }^{* * *}=p<0.001, * * * *=p<0.0001$ by ANOVA with Bonferroni's post hoc test for multiple comparisons. Western blot analyses on extracts from PC3 cells expressing miR137 or scramble controls confirmed the reduced protein levels including in the case of SUZ12 (K.). Thus SUZ12 protein was decreased in PC3 cells over-expressing miR137, suggesting potential post-translational regulation of SUZ12 protein levels by miR137. qRTPCRs and western analyses were completed on a minimum of three biological replicates. 
To confirm these findings RNAhybrid [39] was used to calculate the minimum free energy for hybridization of miR137 with target UTRs where we had evidence indicating that miR137 decreases both mRNA and protein expression. We compared the calculated minimum free energy for known validated miR137 targets KDM1A $(-19.4 \mathrm{kcal} / \mathrm{mol})$ and $N C o A 2(-19.9 \mathrm{kcal} / \mathrm{mol})$. To test if $K D M 2 A, K D M 4 A, K D M 5 B, K D M 7 A$ and $M E D 1$ are direct targets of $m i R 137$ we generated luciferase reporter constructs using the psiCHECK2 vector containing the predicted miR137 target sequences identified within the 3'UTR of each putative novel target (Figure 4A-4E). Each reporter was cotransfected into PC3 cells with either the miR137 or miR-scrambled control expression construct. Over-expression of miR137 had no effect on luciferase reporter activity of the parental psiCHECK2 vector (data not shown), whereas over-expression of miR137 caused a significant decreases in the relative luciferase reporter activity for each of the psiCHECK2 constructs harboring the putative 3'UTR target sequences for each gene, as compared to cells transfected with the scrambled miR negative control (Figure 4). This suggests that $K D M 2 A$, $K D M 4 A, K D M 5 B, K D M 7 A$ and $M E D 1$ are direct targets of $\operatorname{miR} 137$.

\section{Regulation of $\mathrm{miR} 137$ expression in prostate cancer cells}

We next assessed the relationship between androgen and miR137 expression. To this end, we used the integrated genome viewer [40] and the appropriate genome build to interrogate publically available AR genomewide chromatin immune-precipitation (ChIP) (GSE22076, GSE28219, GSE48308,GSE14092/97) datasets and identified AR recruitment to the miR137 locus in androgen responsive, non-malignant muscle cells [41] (Figure 5A). Consistent with this, androgen treatment of androgen responsive LNCaP cells induced miR137 expression (Figure 5B). We and others have previously shown that $K D M 1 A$ is a crucial component of androgen induced and AR-mediated transcription in PCa cells [14-17, 42, 43]. We therefore tested whether KDM1A is involved in androgen regulation of $m i R 137$ expression. To this end we used siRNA to functionally deplete $K D M 1 A$ expression in LNCaP cells (Figure 5C) as previously described [14]. We found that KDM1A is required for androgen-induced miR137 expression (Figure 5C, 5D).

\section{Effect of $m i R 137$ expression on androgen target gene expression in prostate cancer cells}

Collectively our data support a rheostat function for $m i R 137$ in the autoregulation of androgen signaling, as depicted in Figure 5E. In non-malignant androgen responsive cells, $\mathrm{AR} /$ cofactor complexes, including KDMs, drive hormone-dependent transcription of target gene networks. This response is attenuated by induction of miR137 expression, which reduces levels of essential AR coregulators. In malignant androgen responsive cells, the miR137 locus can be epigenetically silenced by DNA methylation, allowing a sustained androgen response to drive androgenic proliferation pathways. Consistent with this, alterations in expression of these coregulators are associated with poorer PCa outcomes (Supplemental Figure 2B, 2C). To further test this model of miR137 as a negative regulator of androgen-dependent transcription, we assayed the effect of a synthetic miR137 antagomiR on androgen-induced expression of the prostate specific antigen gene, $P S A / K L K 3$. As shown in Figure 5F, androgen treatment of $\mathrm{LnCaP}$ cells stimulated a $\sim 6$ fold induction in PSA/KLK3 expression. However functional inhibition of miR137 by transfection of anti-miR137 in LnCaP cells resulted in a $\sim 9$ fold androgen induction of $P S A / K L K 3$ expression. Moreover ectopic expression of
A
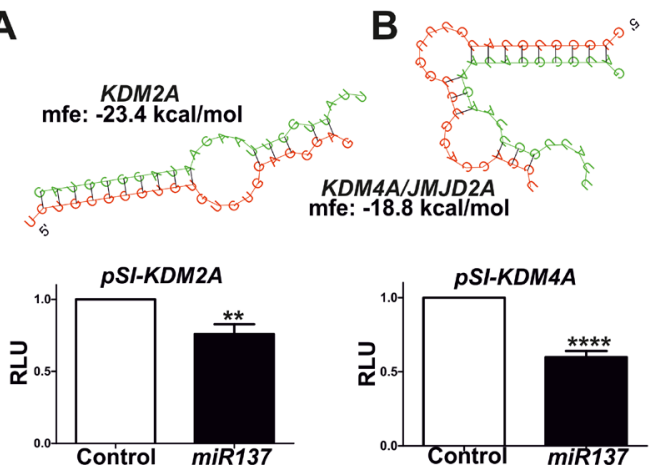
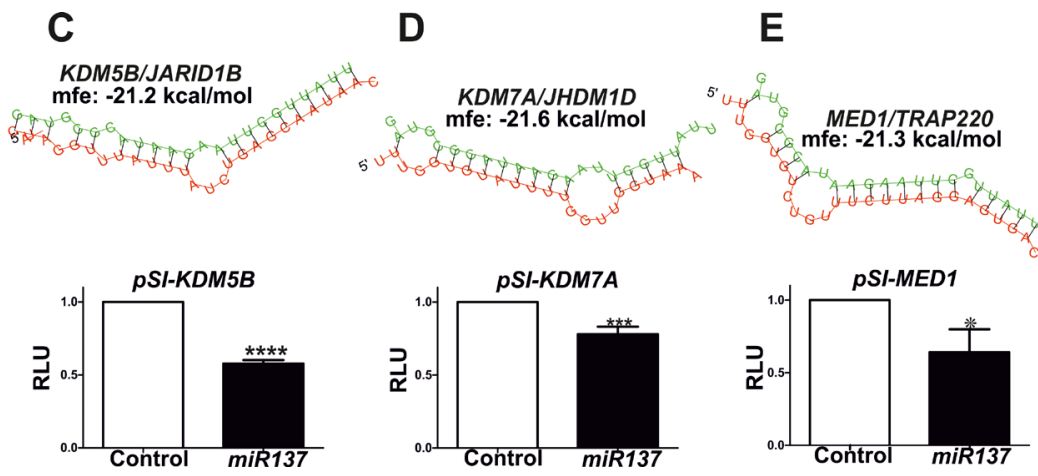

Figure 4: The RNAhybrid algorithm was used to determine the predicted hybridization of miR137 (green) and the 3'UTRs of the novel putative miR137 targets as indicated, and luciferase reporter assays used to confirm target specificity: A., KDM2A B., KDM4A C., KDM5B D., KMD7A and E., MED1. Luciferase assays were performed in PC3 cells transfected with either parental psiCHECK2 or psiCHECK2-3'UTR constructs for each putative miR137 target and either a scrambled control or $m i R 137$ expression construct. Bars represent mean \pm SEM of minimum of three biological replicate experiments conducted on at least three independent occasions $(n=6-9){ }^{*}=p<0.05 ; * * p<0.005,{ }^{* * *}=p<0.001, * * * *=p<0.0001$ by $t$ test. 

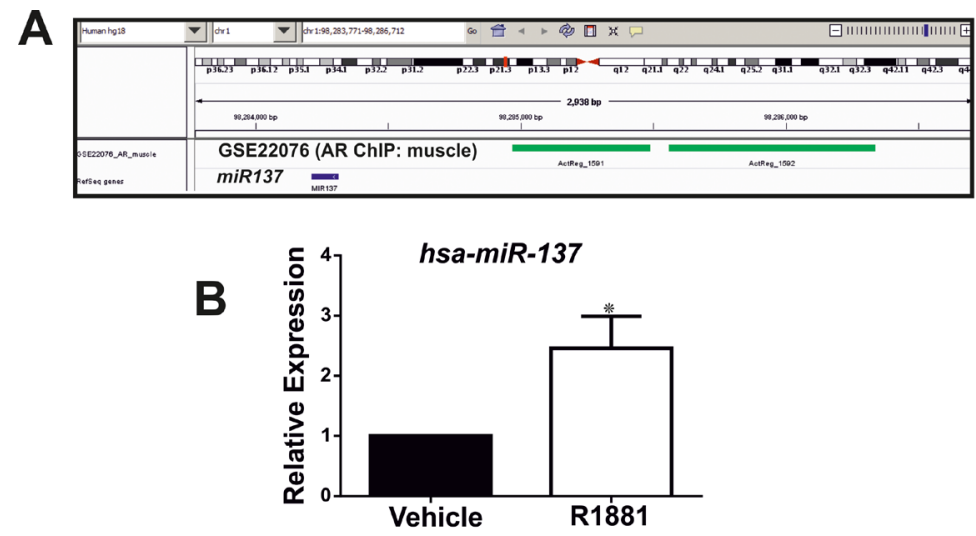

C

D
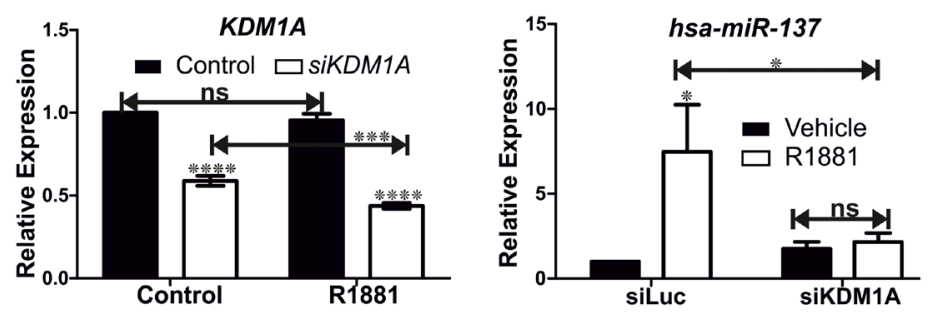

E

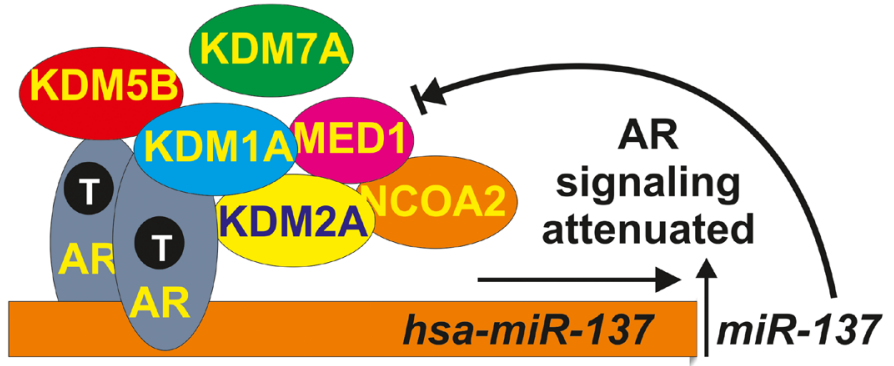

$\mathbf{F}$

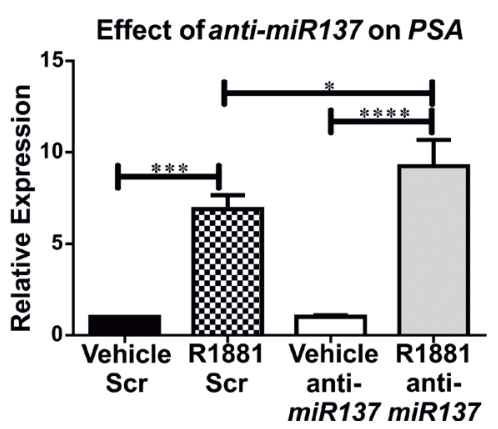

G

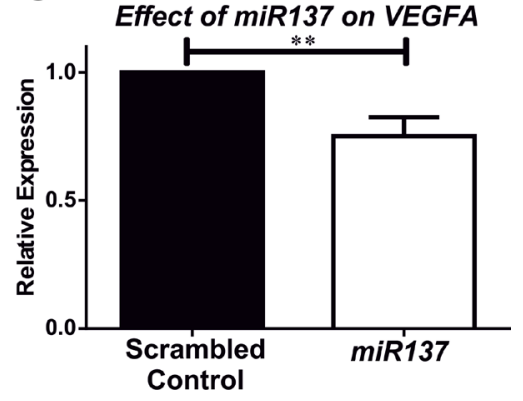

Figure 5: A. Genomewide chromatin immune-precipitation (ChIP) assays (GSE22076) determined the distribution of the AR in muscle cells [41] indicate recruitment of AR (indicated in green) to the miR137 locus (indicated in blue). B. Quantitative RTPCR indicates expression of miR137 induced by androgen in LnCaP cells. C., D. siRNA mediated functional depletion of KDM1A indicates androgen induced expression of $m i R 137$ requires KDM1A. There is a significant reduction in KDM1A expression in LNCaP treated with both siKDM1A with androgen as compared to LNCaP treated with siKDM1A and vehicle. This suggests that androgen induction of miR137 augments siRNA mediated depletion of KDM1A. Data shown is the mean \pm SEM of a minimum of five biological independent experiments analyzed in triplicate. E. We propose a model whereby androgens, acting via the AR-coregulator complex induce expression of miR 137 which in turn acts to reduce coregulator levels and attenuate androgen transcriptional activation. The AR is known to interact with KDM1A, KDM2A, KDM5B, NCOA2 and MED1 whereas AR interaction with KDM7A has not been reported to date. F. Consistent with this model, quantitative RTPCR indicates a synthetic miRl37 antagomiR significantly enhances androgen induced transcription of $P S A / K L K 3$ in LnCaP cells. AntiMiR experiments were conducted on a minimum of six biological replicates analyzed in technical triplicates. G. Conversely ectopic expression of miR 137 reduces expression of the pro-angiogenic KDM1A target gene in the PC3 cell model of castrate resistant PCa. Data shown is the mean \pm SEM of a minimum of three independent experiments analyzed in triplicate. $*=p<0.05 ; * * p<0.005, * * *=p<0.001, * * * *=p<0.0001$. 
miR137 reduces expression of the VEGFA pro-angiogenic factor (Figure 5G) which we have previously shown to be regulated by KDM1A [14]. Taken together our results provide strong evidence for a central role of miR137 as a rheostat controlling androgen response in prostate cells. Induction of miR137 by AR executes a negative feedback loop by suppressing expression of essential AR coregulators, in particular the KDMs, as outlined here. Disruption of this pathway may therefore play a key role in disease progression in $\mathrm{PCa}$.

\section{DISCUSSION}

There is considerable interest in the potential clinical value of $m i R s$ in PCa [44]. However, the successful exploitation of miRs as clinical prognostic markers and their utilization as therapeutic targets will require comprehensive molecular characterization of the diverse effects of individual miRs in distinct cellular contexts. It was previously established that miR137 negatively regulates many genes implicated in cancer including the transcriptional coregulators $K D M 1 A[4,6,45]$ and NCOA2 $[13,38]$, aurora kinase A (AURKA) [6], estrogen-related receptor $E R R \alpha / N R 3 B 1$ [12] and constitutive androstane receptor $(C A R / N F 113)[46]$, the $C D C 42$ and $C D K 6$ cell cycle regulators [7, 47], the ubiquitin ligase $M I B 1[48]$, COX2 [5], paxillin [49], chromosome segregation like1 CSE1L gene [50], glioma pathogenesis-related protein 1 (also referred to as RTVP1) [51], the EZH2 polycomb protein [52] and $C t B P 1$ [53]. Interestingly, loss or reduced expression of $m i R 137$ has been reported in colo-rectal cancer [6], neuroblastoma [4], glioblastoma [51], head and neck [10], non-small cell lung [54, 55] and gastric [56] cancers. This loss or reduction in miR137 expression is commonly attributable to epigenetic silencing by DNA methylation. In this study we show that the miR137 locus is unmethylated in non-malignant PREC, but is increasingly methylated in more aggressive $\mathrm{PCa}$ cell lines (Figure 1C). Consistent with this, our analysis of the TCGA DNA methylation datasets confirms increased DNA methylation of the miR137 locus in all cancers examined with the exception of thyroid carcinoma. Indeed increased methylation of miR137 was found in higher grade PCas (Figure 1). Furthermore there is evidence in the TCGA prostate dataset presented in the cBioPortal that up to $10 \%$ of prostate tumors harbor heterozygous deletions encompassing the miR137 locus [57]. Restoration of $m i R 137$ expression inhibits proliferation and the metastatic potential of colo-rectal cancer $[6,7,49]$ and glioblastoma [51] and sensitizes cancer cells to chemotherapies [46, 58]. Collectively these numerous studies support an important role for epigenetic silencing of miR137 in carcinogenesis, resistance to apoptosis, promotion of metastases and mediating multiple mechanisms of therapeutic resistance. It is in this context that we have identified five nuclear receptor transcriptional coregulators as novel targets of miR137. Our work expands the known repertoire of validated $m i R 137$ targets as we have identified an extended network of known and potential AR transcriptional coregulators as novel miR137 targets.

The AR plays essential roles in carcinogenesis and metastases, most notably in prostate and bladder cancers [59]. For this reason, androgen deprivation therapies (ADTs) are commonly used to treat PCa. Although ADTs are often initially effective, a transition to a hormone refractory state in which androgen-targeted therapies are no longer effective appears inevitable even for next generation ADTs such as abiraterone and enzalutamide [as reviewed in 60]. Indeed, it is now understood that androgen signaling persists following the transition to the hormone refractory, castrate resistant state $[19,60,61$, 62]. Current ADTs directly target AR function by blocking androgen biosynthesis (gonadotrophin releasing hormone analogues), acting as AR selective antagonists (flutamide, bicalutamide, enzalutamide) or blocking intra-tumoral androgen biosynthesis (abiraterone). However men receiving ADT commonly progress within 18 months to a castration resistant state for which no curative therapy is available. Given the essential roles for androgen signaling in all PCa stages, there is an urgent need to identify novel components of the AR signaling network which may represent novel $\mathrm{PCa}$ therapeutic targets. AR coregulators are attractive therapeutic targets as the AR must recruit a large repertoire of enzymatically diverse transcriptional coregulators. Indeed many of these AR coregulators are implicated in PCa through diverse molecular mechanisms [63]. These include AR coregulators with intrinsic or recruited lysine acetyltransferase (KATs) activity such as the p160 (NCOA1, NCOA2, NCOA3) and p300/ CBP coactivators [28, 63-69], lysine methyltransferases (KMTs) such as G9A and SYMD3 [70, 71], lysine demethylases (KDMs) such as KDM1A/LSD1 [16, 42], KDM4A/JMJD2A [72, 20], JMJD2C [15], JMJD2D [72], KDM5B/JARID1B [30] and the MED1 component of the mediator complex [73].

MiR137 represses KDM1A [6] and NCOA2 [38]. Although epigenetic loss of miR137 contributes to increased $K D M 1 A$ expression in colo-rectal [6] and oral [38] cancers respectively, the mechanisms resulting in increased $K D M 1 A$ and NCOA2 in PCa cells are not well understood. NCOA1, NCOA2 and NCOA3 are miR137 targets in prostate, breast and melanoma cancers and the miR137 locus is silenced in PCa [13]. In our study we have confirmed that miR137 is epigenetically silenced in pre-clinical PCa cell models of localized and castrate resistant cancer and demonstrate that increased miR137 methylation correlates with increasing Gleason grade in a clinical dataset (Figure 1). Furthermore, we have shown that miR137 is predicted to act as a repressor of an extended network of transcriptional coregulators, in addition to KDM1A (Supplemental Table, Figure 1). We first confirmed expression of the putative novel miR137 
targets (KDM2A, KDM5B, KDM7A, CBP, SUZ12, $M E D 1)$ and the KDM1A and NCOA2 validated miR137 targets in PCa cell lines (Figure 2). Ectopic expression of miR137 in PC3 cells, which lack intrinsic miR137 expression, results in decreased mRNA and protein levels of KDM1A, KDM2A, KDM4A, KDM5B, KDM7A and MEDI but had no effect on $C B P$ or SUZ12 mRNA levels (Figure 3). However protein levels of SUZ12 were decreased, suggesting miR137 interferes with SUZ12 protein levels through an alternative mechanism. Related to this, miR137 is known to regulate the EZH2 component of the polycomb repressive complex 2 (PRC2) of which SUZ12 is also an integral component [52]. It is possible that miR137 mediated depletion of EZH2 induces dissociation of PRC2 thereby contributing to decreased SUZ12 observed here. In addition we found that miR137 repressed luciferase reporters containing the predicted miR137 target sequences from the 3'UTR of KDM2A, KDM4A, KDM5B, KDM7A and MED1. Collectively, our data supports $m i R 137$ as a negative regulator for the transcriptional KDM2A, KDM4A, KDM5B, KDM7A and $M E D 1$ in PCa cells.

NCOA2, KDM1A, KDM4A, KDM5B and MED1 are AR coregulators implicated in prostate and other cancers [16, 30, 65, 73-78]. KDM1A promotes $\mathrm{PCa}$ recurrence by enhancing androgen induced proproliferative and pro-angiogenic transcription $[14,17]$. Similarly, NCOA2, more commonly referred to as SRC2/ TIF2 is a p160 AR coactivator implicated as an oncogene in prostate carcinogenesis and castrate resistance [74-78]. KDM2A/JHDM1A/FBXL11 acts on histone mono- and dimethylated histone H3K36 and is implicated in lung cancer [79] and the epigenetic silencing of chromatin [80]. The tri-methyl selective KDM4A/JMJD2A demethylase is an AR coregulator [72] expressed in $\mathrm{PCa}$ [14] and is a determinant of mTOR inhibitor sensitivity in non-small cell lung cancer patients [81]. Several studies have confirmed that the histone $\mathrm{H} 3$ lysine 4 selective demethylase, KDM5B interacts with AR, acts as an AR transcriptional coactivator, is increased in $\mathrm{PCa}$ and can act as an oncogene [30,82 and references therein, 82-85]. KDM7A/JHDM1D/KIAA1718 is a dualspecificity demethylase which removes repressive marks on histone-H3, lysine 9 and 27 (H3K9me, H3K27me) $[86,87]$. There is evidence that related members of this JHDM1-family of demethylases function as nuclear receptor transcriptional coregulators [88] and are implicated in $\mathrm{PCa}$ [76]. Given the ability of KDM7A to remove histone lysine methylation marks commonly associated with transcriptional repression (H3K9/K27) it is possible that KDM7A can also promote androgen induced transcription. However there is also evidence that in certain contexts increased JHDM1D can act as a tumor suppressor [89]. Further work is required to delineate the specific functions of these KDMs in PCa cells. KDMs are attractive therapeutic targets and the availability of next generation KDM selective inhibitors [43, 90, 91] raises the potential for development of novel therapies which can circumvent resistance to existing ADTs by targeting the KDM activities required for the functional AR-complex.

As little is known about the regulation of miR137 in prostate cells, we interrogated publically available ChIP datasets and identified AR recruitment to the miR137 locus in non-malignant cells (Figure 5A). Based on this finding we tested the potential for androgen regulation of $m i R 137$ and found a significant induction of miR137 expression in the androgen responsive $\mathrm{LnCaP}$ which possess hemi-methylated miR137 loci (Figure 5B). Thus androgens induce a negative regulator of AR-associated coregulators. We next determined whether KDM1A participates in androgen regulation of miR 137 expression. To address this we used established siRNA methods to functionally deplete KDMIA in LnCaP cells (Figure 5C) [14]. Consistent with our previous result (Figure 5B), expression of $m i R 137$ is increased by androgen, but this androgen induction of miR137 requires KDM1A (Figure 5D). Furthermore, there is a significant reduction in $K D M 1 A$ expression in $\mathrm{LNCaP}$ treated with both siKDM1A with androgen as compared to $\mathrm{LNCaP}$ treated with $\operatorname{siKDM1A}$ and vehicle. This suggests that androgen induction of miR137 augments siRNA mediated depletion of KDM1A (Figure 5C).

Our study has identified a negative feedback mechanism whereby androgens can attenuate androgen responsivity by titrating the levels of important coregulators through expression of miR137 (Figure 5). We hypothesized that impairment or loss of androgen induction of miR137 due to aberrant methylation of the miR137 locus would relieve this brake on coregulator levels and would amplify androgen signaling. To test this we used a synthetic miR137 antagomiR to inhibit miR137. We found that functional interference of $m i R 137$ in $\mathrm{LnCaP}$ cells (Figure 1B) induces a 9 fold androgen induction of $P S A / K L K 3$ expression, as compared to a 6-fold induction of $P S A / K L K 3$ expression obtained in androgen treated LnCaP cells transfected with a scrambled antagomiR (Figure 5F). Therefore, we show that loss of miR137 promotes androgen induced transcription. Conversely, the ability of a single miR to interfere with expression of multiple target genes emphasizes the great potential in therapeutic targeting of miRs. Although significant pharmacologic barriers remain to the deployment of miRs as systemic cancer therapies, we tested the effect of restoration of miR137 in the PC3 model of advanced castrate resistant $\mathrm{PCa}$. We found that restoration of miR137 expression decreases expression of the proangiogenic factor VEGFA (Figure 5G), a key mediator of $\mathrm{PCa}$ metastases and therapy resistance [59].

In conclusion, our data indicates that miR137 executes an androgen driven feedback inhibition of multiple AR coregulators in normal prostate epithelia and early stage PCa. Conversely, miR137 silencing in 
advanced disease promotes over-expression of these coregulators and in turn hyper-activation of AR signaling. The ability of miR 137 to modulate AR signaling supports $m i R 137$ as a potential therapeutic target for preventing or delaying prostate carcinogenesis and progression. Future studies should also focus on the multiple epigenetic effects attributable to the loss of miR137. Our study further highlights the important role of reciprocal regulatory networks involving microRNAs, nuclear receptors and coregulators in PCa. Our data supports the development of new therapies targeting epigenetic coregulators as a mechanism to overcome resistance to ADTs which currently target the AR but not the associated coregulator components of the AR complex.

\section{MATERIALS AND METHODS}

\section{Bioinformatics: miR target prediction, clinical correlation, protein network analysis and statistics}

A survey of putative targets of miR137 was conducted using PicTar [32], TargetScan [33], miRDB [34], and miRanda (microRNA.org) target prediction algorithms [35, 92]. RNAhybrid was used to determine the minimum free energy requried for hybridization of $m i R 137$ and the predicted novel targets [39]. Candidates identified by a minimum of two prediction algorithms and with a known function in transcripion were selected for further analysis. The MethHC tool [36] was used to statistically compare methylation of the miR137 locus in tumor and non-tumor tissue from the TCGA database. The UCSC cancer genome browser [93] was used to correlate miR137 locus methylation with PCa recurrence. Statistical analysis was performed using GraphPad Prism 5.04 (GraphPad, La Jolla, CA). For qPCR and luciferase reporter experiments t-tests, one-way ANOVA with Dunnett's and/or Bonferroni post-test multiple comparison test was performed using GraphPad Prism. $P$-values $<0.05$ were considered statistically significant with $95 \%$ confidence intervals.

\section{Cell culture, transfection, siRNA, androgen (R1881) treatments}

Normal prostate epithelial cells (PREC) and PCa cell lines LNCaP, LNCaP:C4-2 and PC-3 cells were maintained as described previously [14, 94]. PREC were sourced from Lonza (Walkersville, MD), LnCaP and $\mathrm{PC} 3$ were purchased from ATCC. LnCaP:C4-2 were a generous gift from Dr. Doug Scherr, Department of Urology, Weill Cornell Medical College. Androgen treatment (R1881) and siRNA depletion of KDM1A and luciferase as negative control were conducted as previously described $[14,95]$. PC3 cells were stably transfected with over-expression constructs for human
miR137 and scrambled controls (\#HmiR0011-MR04 and \#CmiR0001-MR04, GeneCopoeia, Inc.), using Lipofectamine 2000 (Invitrogen). Transfection efficiency was $80-90 \%$ as assessed by GFP expression and stable transfectants selected using puromycin $(4 \mu \mathrm{g} / \mathrm{ml})$. Total RNA and protein were isolated from three independent stably transfected PC3 lines expressing miR137 or the scrambled control.

\section{DNA methylation analysis, RNA extraction and Taqman real-time PCR}

The methylation status of the miR137 locus in PREC, LNCaP, LNCaP:C4-2 and PC-3 cells was determined by performing methylation specific analysis on bisulfite modified DNA essentially as previously described [6]. Genomic DNA (350ng) was subject to bisulfite conversion using the EZ-DNA Methylation Kit (\#D5001; Zymo Research Corporation, Orange, CA) according to the manufacturer's instructions. The methylation status of the miR137 locus was determined using bisulfite sequencing PCR (BSP) or methylation specific PCR (MSP) [6]. BSP products were cloned into pGEM-T (Promega, Southampton, UK), transformed into SURE E.coli competent cells (Stratagene/Agilent Technologies, Wokingham, UK). A minimum of 10 independent colonies were selected and plasmids containing the BSP inserts were sequenced directly to assess percentage methylation [96].

RNA (miRNA and total) was extracted using miRNeasy Mini kit (Qiagen, Crawley, UK) according to manufacturer's instructions. For miRNA quantitative reverse transcription polymerase chain reaction (qPCR) expression analysis, RNA $(1 \mu \mathrm{g})$ was reverse transcribed using the miScript reverse transcription kit (Qiagen, Crawley, UK) and miR-specific assays for human miR137 (MS00003486) and the RNUD6 (218293) and/or snoRD6 (MS00033705) normalization controls (Qiagen, Crawley, UK). For mRNA expression analysis, RNA $(1 \mu \mathrm{g})$ was reverse transcribed using qScript cDNA SuperMix (Quanta Biosciences, VWR, Lutterworth, UK) [14]. The resulting cDNA was used as a template for hydrolysis probe qPCR using the following gene specific hydrolysis probe assays (Invitrogen/Life Technologies/Thermo Scientific, Renfrew, UK): KDM1A (Hs01002741_m1), KDM2A (Hs00367034_m1), KDM4A (Hs00206360_m1), KDM5B (Hs00981910_m1), KDM7A (Hs01398501_m1), MED1 (Hs01062349 m1), NCoA2 (Hs00896114 m1), CBP (Hs00231733_m1), SUZ12 (Hs00248742_m1), VEGFA (Hs00900055_m1) and GAPDH (Hs03929097g1). All qPCR experiments were carried out on a minimum of three independent RNA isolations analyzed in triplicate. 
Table 1.

\begin{tabular}{|c|c|c|}
\hline Gene & Forward (5'-3') & Reverse (5'-3') \\
\hline $\mathrm{KDM} 2 \mathrm{~A}$ & ccgetcgaggaagccctacagagttagggaatg & ataagaatgcggecgcagtttctttctaaggccagttaatg \\
\hline KDM4A & ccgctcgagcccaggattggagggcttcacacc & ataagaatgcggccgccattttattgctaaggacaaggtgatgc \\
\hline KDM5B & ccgctcgaggaaattccagtaaatcctcatttg & ataagaatgcggccgcaatcgctaaagcaccaacacac \\
\hline KDM7A & ccgctcgaggtaagaacactgcccgaagaacag & ataagaatgcggccgcgaaaatacatcaagacactaccaac \\
\hline MED1 & ccgctcgaggtgcatgtatatgaagggctggg & ataagaatgcggccgcccatgactcaaacggacaactac \\
\hline
\end{tabular}

Table 2.

\begin{tabular}{|l|l|l|}
\hline Coregulator & Histone substrate & Non-histone substrates \\
\hline KDM1A(LSD1/AOF1) & H3K4me2/1; H3K9me2/1 & p53, E2F1, SNMT1 \\
\hline KDM2A (JHDM1A/FBXL11) & H3K36me2/1 & p65, NF-kB \\
\hline KDM4A (JMJD2A) & H3K9me3;H3K36me3, H1.4K26me3/2 & \\
\hline KDM5B (JARID1B) & $\mathrm{H} 3 \mathrm{~K} 4 \mathrm{me} 3 / 2$ & \\
\hline KDM7A (JHDM1D/KIAA1718) & $\mathrm{H} 3 \mathrm{~K} 9 \mathrm{me} 2 / 1 ; \mathrm{H} 3 \mathrm{~K} 27 \mathrm{me} 2 / 1$ & \\
\hline MED1 (DRIP205/TRAP220) & histone acetylation via CBP/p300 & \\
\hline NCOA2 (SRC2/TIF2) & intrinsic histone acetylation and via CBP/p300 & \\
\hline
\end{tabular}

\section{miR target validation}

Luciferase reporter contructs were generated containing the predicted miR137 target sequences from 3'-UTRs of each of the identified putative miR137-targets with a known role in transcription (KDM1A, KDM2A, KDM4A, KDM5B, KDM7A, MED1, and NCoA2). $N C O A 2$ has previously been shown to be a direct miR137 target and was therefore included as a positive control target 3'-UTR. The predicted miR137 target sequences identified within the 3'UTR of the putative novel targets were cloned into XhoI and NotI sites of the psiCHECK2 luciferase reporter construct (Promega) using the primers indicated (Table 1). An empty psiCHECK2 vector was used as negative control. Plasmid DNA for overexpression constructs for human miR137 and scrambled controls (\#HmiR0011-MR04 and \#CmiR0001-MR04, GeneCopoeia, Inc. Rockville, MD), psiCHECK2 negative control and psiCHECK2-3'UTR constructs for the identified targets were prepared using Prepease endotoxin free midiprep kit (USB). PC3 cells $\left(1 \times 10^{5}\right)$, which lack endogenous miR137 expression (Figure 1C), were plated in 24-well plates and allowed to attach for 24 hours prior to transfection. Cells were transfected with constructs expressing miR137 or a scrambled control and either the psiCHECK2 empty vector control or psiCHECK2 containing the 3'UTR of the putative miR137 targets of the genes identified. A total of 500ng DNA was used per well and cells were transfected using lipofectamine 2000 (Invitrogen/LifeTechnologies/ThermoScientific) according to the manufacturer's instructions. After 48 hours, cells were harvested and luciferase activity measured using the dual luciferase assay system (Promega) with a Turner TD-20/20 luminometer (Turner Designs, Sunnyvale, CA) as previously described [97]. Data were normalized to firefly luciferase. Luciferase experiments were conducted in triplicate and repeated on three independent occasions. The miR137 antagomiR (MIN0000429) was purchased from Qiagen and transfected into LNCaP cells using lipofectamine 2000 (Invitrogen/ Life Technologies/ ThermoScientific) according to the manufacturer's directions. Cells were grown at $37 \mathrm{oC}$ for 72 hours prior to RNA isolation and quantitative RTPCR as described earlier.

\section{Western blotting}

For protein expression analysis, after three days in culture PC-3-miR137 and PC-3-scrambled control expressing cells were washed with PBS and lysed in SDS denaturing buffer $(100 \mathrm{mM}$ Tris- $\mathrm{HCl} \mathrm{pH} 6.8,4 \%$ SDS and $20 \%$ glycerol). The protein concentration in the cell lysates was quantified using the Bio-Rad DC Protein assay (Bio-Rad, Hercules, USA). Protein samples $(10 \mu \mathrm{g})$ were boiled in loading buffer ( $83 \mathrm{mM}$ Tris $\mathrm{pH} 8.8,30 \%$ sucrose, $0.00083 \%$ bromophenol blue, $3 \%$ SDS and $8.3 \mathrm{mM}$ DTT) for 5 minutes, separated on 10\% SDS-PAGE gels, and transferred to polyvinylidene difluoride membranes (Millipore Corporation, Bedford, USA). Membranes were blocked in 5\% non-fat-milk for 1 hour and probed with primary antibodies against KDM2A/JHDM1A (Thermo Scientific; \#PA5-11177; $5 \mu \mathrm{g} / \mathrm{ml}$ ), KDM4A/ 
JMJD2A (Cell Signaling Technology, Danvers, MA; \#3393; 1:500), KDM5B/JARID1B (Cell Signaling; \#3273; 1:1000), KDM7A/JHDM1D (Sigma-Aldrich, Gillingham, UK; \#SAB2101190; $1 \mu \mathrm{g} / \mathrm{ml}$ ), MED1/TRAP220 (R\&D Systems, Abingdon, UK; \#AF5520; $1 \mu \mathrm{g} / \mathrm{ml})$, SUZ12 (Cell Signaling; \#3737; 1:1000), NCoA2/TIF2 (BD Transduction Laboratories, Oxford, UK; \#610985; 0.25 $\mu \mathrm{g} / \mathrm{ml}$ ), and GAPDH (Abcam, Cambridge, UK; \#ab9484; $1 \mu \mathrm{g} / \mathrm{ml}$ ) at $4{ }^{\circ} \mathrm{C}$ overnight. Secondary antibodies used were donkey anti-goat, goat anti-mouse and goat antirabbit conjugated with horseradish peroxidase (Santa Cruz Biotechnology, Inc., Wembley, UK). Antibody binding was visualized using Amersham ECL Prime Western Blotting Detection Reagent (GE Healthcare, Amersham, UK). Western blots were performed on whole cell extracts from three independent transfections.

\section{ACKNOWLEDGEMENTS}

The authors are grateful to members of the Mongan, Gudas and Persson laboratories for helpful discussions. The authors are particularly grateful to Dr. Pei-Chun Lin and Dr. Mark Rubin for helpful discussions. This research was supported in part by NIH-R01CA043796 and funds from Weill Cornell Medical College (LJG), a Teggers Foundation postdoctoral fellowship (EMN), the BBSRCDTP (JW, DMH, NPM) and the University of Nottingham international collaboration fund (NPM).

\section{CONFLICTS OF INTEREST}

The authors confirm no conflict of interest related to the current project.

\section{REFERENCES}

1. Suzuki H, Maruyama R, Yamamoto E and Kai M. DNA methylation and microRNA dysregulation in cancer. Molecular oncology. 2012; 6(6):567-578.

2. Ambros V. The functions of animal microRNAs. Nature. 2004; 431(7006):350-355.

3. Lin PC, Chiu YL, Banerjee S, Park K, Mosquera JM, Giannopoulou E, Alves P, Tewari AK, Gerstein MB, Beltran H, Melnick AM, Elemento O, Demichelis F and Rubin MA. Epigenetic repression of miR-31 disrupts androgen receptor homeostasis and contributes to prostate cancer progression. Cancer research. 2013; 73(3):12321244.

4. Althoff K, Beckers A, Odersky A, Mestdagh P, Koster J, Bray IM, Bryan K, Vandesompele J, Speleman F, Stallings RL, Schramm A, Eggert A, Sprussel A and Schulte JH. MiR-137 functions as a tumor suppressor in neuroblastoma by downregulating KDM1A. International journal of cancer Journal international du cancer. 2013; 133(5):1064-1073.

5. Chen L, Wang X, Wang H, Li Y, Yan W, Han L, Zhang K,
Zhang J, Wang Y, Feng Y, Pu P, Jiang T, Kang C and Jiang C. miR-137 is frequently down-regulated in glioblastoma and is a negative regulator of Cox-2. Eur J Cancer. 2012; 48(16):3104-3111.

6. Balaguer F, Link A, Lozano JJ, Cuatrecasas M, Nagasaka T, Boland CR and Goel A. Epigenetic silencing of miR-137 is an early event in colorectal carcinogenesis. Cancer research. 2010; 70(16):6609-6618.

7. Liu M, Lang N, Qiu M, Xu F, Li Q, Tang Q, Chen J, Chen X, Zhang S, Liu Z, Zhou J, Zhu Y, Deng Y, Zheng Y and Bi F. miR-137 targets Cdc42 expression, induces cell cycle G1 arrest and inhibits invasion in colorectal cancer cells. International journal of cancer Journal international du cancer. 2011; 128(6):1269-1279.

8. Vrba L, Munoz-Rodriguez JL, Stampfer MR and Futscher BW. miRNA gene promoters are frequent targets of aberrant DNA methylation in human breast cancer. PloS one. $2013 ; 8(1)$ :e54398.

9. Tu HF, Lin SC and Chang KW. MicroRNA aberrances in head and neck cancer: pathogenetic and clinical significance. Current opinion in otolaryngology \& head and neck surgery. 2013; 21(2):104-111.

10. Langevin SM, Stone RA, Bunker CH, Lyons-Weiler MA, LaFramboise WA, Kelly L, Seethala RR, Grandis JR, Sobol RW and Taioli E. MicroRNA-137 promoter methylation is associated with poorer overall survival in patients with squamous cell carcinoma of the head and neck. Cancer. 2011; 117(7):1454-1462.

11. Shimizu T, Suzuki H, Nojima M, Kitamura H, Yamamoto E, Maruyama R, Ashida M, Hatahira T, Kai M, Masumori $\mathrm{N}$, Tokino $\mathrm{T}$, Imai $\mathrm{K}$, Tsukamoto $\mathrm{T}$ and Toyota $\mathrm{M}$. Methylation of a panel of microRNA genes is a novel biomarker for detection of bladder cancer. European urology. 2013; 63(6):1091-1100.

12. Zhao Y, Li Y, Lou G, Zhao L, Xu Z, Zhang Y and He F. MiR-137 targets estrogen-related receptor alpha and impairs the proliferative and migratory capacity of breast cancer cells. PloS one. 2012; 7(6):e39102.

13. Eedunuri VK, Rajapakshe K, Fiskus W, Geng C, Chew SA, Foley C, Shah SS, Shou J, Mohamed JS, Coarfa C, O'Malley BW and Mitsiades N. miR-137 Targets p160 Steroid Receptor Coactivators SRC1, SRC2, and SRC3 and Inhibits Cell Proliferation. Mol Endocrinol. 2015; 29(8):1170-1183.

14. Kashyap V, Ahmad S, Nilsson EM, Helczynski L, Kenna S, Persson JL, Gudas LJ and Mongan NP. The lysine specific demethylase-1 (LSD1/KDM1A) regulates VEGF-A expression in prostate cancer. Molecular oncology. 2013; 7(3):555-566.

15. Wissmann M, Yin N, Muller JM, Greschik H, Fodor BD, Jenuwein T, Vogler C, Schneider R, Gunther T, Buettner $\mathrm{R}$, Metzger E and Schule R. Cooperative demethylation by JMJD2C and LSD1 promotes androgen receptor-dependent gene expression. Nature cell biology. 2007; 9(3):347-353. 
16. Metzger E, Wissmann M, Yin N, Muller JM, Schneider R, Peters AH, Gunther T, Buettner R and Schule R. LSD1 demethylates repressive histone marks to promote androgen-receptor-dependent transcription. Nature. 2005; 437(7057):436-439.

17. Kahl P, Gullotti L, Heukamp LC, Wolf S, Friedrichs N, Vorreuther R, Solleder G, Bastian PJ, Ellinger J, Metzger E, Schule R and Buettner R. Androgen receptor coactivators lysine-specific histone demethylase 1 and four and a half LIM domain protein 2 predict risk of prostate cancer recurrence. Cancer research. 2006; 66(23):11341-11347.

18. Mongan NP, Tadokoro-Cuccaro R, Bunch T and Hughes IA. Androgen insensitivity syndrome. Best practice \& research Clinical endocrinology \& metabolism. 2015; 29(4):569-580.

19. Wang Q, Li W, Zhang Y, Yuan X, Xu K, Yu J, Chen Z, Beroukhim R, Wang H, Lupien M, Wu T, Regan MM, Meyer CA, Carroll JS, Manrai AK, Janne OA, et al. Androgen receptor regulates a distinct transcription program in androgen-independent prostate cancer. Cell. 2009; 138(2):245-256.

20. Kauffman EC, Robinson BD, Downes MJ, Powell LG, Lee MM, Scherr DS, Gudas LJ and Mongan NP. Role of androgen receptor and associated lysine-demethylase coregulators, LSD1 and JMJD2A, in localized and advanced human bladder cancer. Molecular carcinogenesis. 2011; 50(12):931-944.

21. Millard CJ, Watson PJ, Fairall L and Schwabe JW. An evolving understanding of nuclear receptor coregulator proteins. Journal of molecular endocrinology. 2013; 51(3):T23-36.

22. Kooistra SM and Helin K. Molecular mechanisms and potential functions of histone demethylases. Nature reviews Molecular cell biology. 2012; 13(5):297-311.

23. Lonard DM and O'Malley BW. Nuclear receptor coregulators: modulators of pathology and therapeutic targets. Nature reviews Endocrinology. 2012; 8(10):598604.

24. Perillo B, Ombra MN, Bertoni A, Cuozzo C, Sacchetti S, Sasso A, Chiariotti L, Malorni A, Abbondanza C and Avvedimento EV. DNA oxidation as triggered by H3K9me2 demethylation drives estrogen-induced gene expression. Science. 2008; 319(5860):202-206.

25. Jin F, Irshad S, Yu W, Belakavadi M, Chekmareva M, Ittmann MM, Abate-Shen C and Fondell JD. ERK and AKT signaling drive MED1 overexpression in prostate cancer in association with elevated proliferation and tumorigenicity. Molecular cancer research : MCR. 2013; 11(7):736-747.

26. Bouchal J, Santer FR, Hoschele PP, Tomastikova E, Neuwirt $\mathrm{H}$ and Culig Z. Transcriptional coactivators p300 and CBP stimulate estrogen receptor-beta signaling and regulate cellular events in prostate cancer. The Prostate. 2011; 71(4):431-437.

27. Geng C, He B, Xu L, Barbieri CE, Eedunuri VK, Chew
SA, Zimmermann M, Bond R, Shou J, Li C, Blattner M, Lonard DM, Demichelis F, Coarfa C, Rubin MA, Zhou P, et al. Prostate cancer-associated mutations in speckle-type POZ protein (SPOP) regulate steroid receptor coactivator 3 protein turnover. Proceedings of the National Academy of Sciences of the United States of America. 2013; 110(17):6997-7002.

28. Zhou XE, Suino-Powell KM, Li J, He Y, Mackeigan JP, Melcher K, Yong EL and Xu HE. Identification of SRC3/ AIB1 as a preferred coactivator for hormone-activated androgen receptor. The Journal of biological chemistry. 2010; 285(12):9161-9171.

29. Frescas D, Guardavaccaro D, Kuchay SM, Kato H, Poleshko A, Basrur V, Elenitoba-Johnson KS, Katz RA and Pagano M. KDM2A represses transcription of centromeric satellite repeats and maintains the heterochromatic state. Cell Cycle. 2008; 7(22):3539-3547.

30. Xiang Y, Zhu Z, Han G, Ye X, Xu B, Peng Z, Ma Y, Yu $\mathrm{Y}$, Lin H, Chen AP and Chen CD. JARID1B is a histone $\mathrm{H} 3$ lysine 4 demethylase up-regulated in prostate cancer. Proceedings of the National Academy of Sciences of the United States of America. 2007; 104(49):19226-19231.

31. Varambally S, Cao Q, Mani RS, Shankar S, Wang X, Ateeq B, Laxman B, Cao X, Jing X, Ramnarayanan K, Brenner JC, Yu J, Kim JH, Han B, Tan P, Kumar-Sinha C, et al. Genomic loss of microRNA-101 leads to overexpression of histone methyltransferase EZH2 in cancer. Science. 2008; 322(5908):1695-1699.

32. Krek A, Grun D, Poy MN, Wolf R, Rosenberg L, Epstein EJ, MacMenamin P, da Piedade I, Gunsalus KC, Stoffel $\mathrm{M}$ and Rajewsky N. Combinatorial microRNA target predictions. Nature genetics. 2005; 37(5):495-500.

33. Lewis BP, Burge CB and Bartel DP. Conserved seed pairing, often flanked by adenosines, indicates that thousands of human genes are microRNA targets. Cell. 2005; 120(1):15-20.

34. Wang X. miRDB: a microRNA target prediction and functional annotation database with a wiki interface. RNA. 2008; 14(6):1012-1017.

35. John B, Enright AJ, Aravin A, Tuschl T, Sander C and Marks DS. Human MicroRNA targets. PLoS biology. 2004; 2(11):e363.

36. Huang WY, Hsu SD, Huang HY, Sun YM, Chou CH, Weng SL and Huang HD. MethHC: a database of DNA methylation and gene expression in human cancer. Nucleic acids research. 2015; 43(Database issue):D856-861.

37. Long Q, Johnson BA, Osunkoya AO, Lai YH, Zhou W, Abramovitz M, Xia M, Bouzyk MB, Nam RK, Sugar L, Stanimirovic A, Williams DJ, Leyland-Jones BR, Seth AK, Petros JA and Moreno CS. Protein-coding and microRNA biomarkers of recurrence of prostate cancer following radical prostatectomy. The American journal of pathology. 2011; 179(1):46-54.

38. Kozaki $\mathrm{K}$, Imoto I, Mogi S, Omura $\mathrm{K}$ and Inazawa J. 
Exploration of tumor-suppressive microRNAs silenced by DNA hypermethylation in oral cancer. Cancer research. 2008; 68(7):2094-2105.

39. Rehmsmeier M, Steffen P, Hochsmann M and Giegerich R. Fast and effective prediction of microRNA/target duplexes. RNA. 2004; 10(10):1507-1517.

40. Robinson JT, Thorvaldsdottir H, Winckler W, Guttman M, Lander ES, Getz G and Mesirov JP. Integrative genomics viewer. Nature biotechnology. 2011; 29(1):24-26.

41. Wyce A, Bai Y, Nagpal S and Thompson CC. Research Resource: The androgen receptor modulates expression of genes with critical roles in muscle development and function. Mol Endocrinol. 2010; 24(8):1665-1674.

42. Cai C, He HH, Gao S, Chen S, Yu Z, Gao Y, Chen MW, Zhang J, Ahmed M, Wang Y, Metzger E, Schule R, Liu XS, Brown $M$ and Balk SP. Lysine-specific demethylase 1 has dual functions as a major regulator of androgen receptor transcriptional activity. Cell reports. 2014; 9(5):1618-1627.

43. Willmann D, Lim S, Wetzel S, Metzger E, Jandausch A, Wilk W, Jung M, Forne I, Imhof A, Janzer A, Kirfel J, Waldmann H, Schule R and Buettner R. Impairment of prostate cancer cell growth by a selective and reversible lysine-specific demethylase 1 inhibitor. International journal of cancer Journal international du cancer. 2012; 131(11):2704-2709.

44. Rane JK, Scaravilli M, Ylipaa A, Pellacani D, Mann VM, Simms MS, Nykter M, Collins AT, Visakorpi T and Maitland NJ. MicroRNA expression profile of primary prostate cancer stem cells as a source of biomarkers and therapeutic targets. European urology. 2015; 67(1):7-10.

45. Sun G, Ye P, Murai K, Lang MF, Li S, Zhang H, Li W, Fu C, Yin J, Wang A, Ma X and Shi Y. miR-137 forms a regulatory loop with nuclear receptor TLX and LSD1 in neural stem cells. Nature communications. 2011; 2:529.

46. Takwi AA, Wang YM, Wu J, Michaelis M, Cinatl $\mathrm{J}$ and Chen T. miR-137 regulates the constitutive androstane receptor and modulates doxorubicin sensitivity in parental and doxorubicin-resistant neuroblastoma cells. Oncogene. 2014; 33(28):3717-3729.

47. Zhu X, Li Y, Shen H, Li H, Long L, Hui L and Xu W. miR-137 inhibits the proliferation of lung cancer cells by targeting Cdc42 and Cdk6. FEBS letters. 2013; 587(1):7381.

48. Smrt RD, Szulwach KE, Pfeiffer RL, Li X, Guo W, Pathania M, Teng ZQ, Luo Y, Peng J, Bordey A, Jin P and Zhao X. MicroRNA miR-137 regulates neuronal maturation by targeting ubiquitin ligase mind bomb-1. Stem Cells. 2010; 28(6):1060-1070.

49. Chen DL, Wang DS, Wu WJ, Zeng ZL, Luo HY, Qiu MZ, Ren C, Zhang DS, Wang ZQ, Wang FH, Li YH, Kang TB and $\mathrm{Xu}$ RH. Overexpression of paxillin induced by miR-137 suppression promotes tumor progression and metastasis in colorectal cancer. Carcinogenesis. 2013; 34(4):803-811.

50. Li KK, Yang L, Pang JC, Chan AK, Zhou L, Mao Y,
Wang Y, Lau KM, Poon WS, Shi Z and Ng HK. MIR137 suppresses growth and invasion, is downregulated in oligodendroglial tumors and targets CSE1L. Brain Pathol. 2013; 23(4):426-439.

51. Bier A, Giladi N, Kronfeld N, Lee HK, Cazacu S, Finniss S, Xiang C, Poisson L, deCarvalho AC, Slavin S, Jacoby E, Yalon M, Toren A, Mikkelsen T and Brodie C. MicroRNA-137 is downregulated in glioblastoma and inhibits the stemness of glioma stem cells by targeting RTVP-1. Oncotarget. 2013; 4(5):665-676.

52. Sun J, Zheng G, Gu Z and Guo Z. MiR-137 inhibits proliferation and angiogenesis of human glioblastoma cells by targeting EZH2. Journal of neuro-oncology. 2015; 122(3):481-489.

53. Deng Y, Deng H, Bi F, Liu J, Bemis LT, Norris D, Wang XJ and Zhang Q. MicroRNA-137 targets carboxyl-terminal binding protein 1 in melanoma cell lines. International journal of biological sciences. 2011; 7(1):133-137.

54. Langevin SM, Stone RA, Bunker CH, Grandis JR, Sobol RW and Taioli E. MicroRNA-137 promoter methylation in oral rinses from patients with squamous cell carcinoma of the head and neck is associated with gender and body mass index. Carcinogenesis. 2010; 31(5):864-870.

55. Zhang B, Liu T, Wu T, Wang Z, Rao Z and Gao J. microRNA-137 functions as a tumor suppressor in human non-small cell lung cancer by targeting SLC22A18. International journal of biological macromolecules. 2015; 74:111-118.

56. Cheng Y, Li Y, Liu D, Zhang R and Zhang J. miR-137 effects on gastric carcinogenesis are mediated by targeting Cox-2-activated PI3K/AKT signaling pathway. FEBS letters. 2014; 588(17):3274-3281.

57. Cerami E, Gao J, Dogrusoz U, Gross BE, Sumer SO, Aksoy BA, Jacobsen A, Byrne CJ, Heuer ML, Larsson E, Antipin Y, Reva B, Goldberg AP, Sander C and Schultz $\mathrm{N}$. The cBio cancer genomics portal: an open platform for exploring multidimensional cancer genomics data. Cancer discovery. 2012; 2(5):401-404.

58. Li P, Ma L, Zhang Y, Ji F and Jin F. MicroRNA-137 down-regulates KIT and inhibits small cell lung cancer cell proliferation. Biomedicine \& pharmacotherapy = Biomedecine \& pharmacotherapie. 2014; 68(1):7-12.

59. Marcinkiewicz K, Scotland KB, Boorjian SA, Nilsson EM, Persson JL, Abrahamsson PA, Allegrucci C, Hughes IA, Gudas LJ and Mongan NP. The androgen receptor and stem cell pathways in prostate and bladder cancers (review). International journal of oncology. 2012; 40(1):5-12.

60. de Brot S, Ntekim A, Cardenas R, James V, Allegrucci C, Heery DM, Bates DO, Odum N, Persson JL and Mongan NP. Regulation of vascular endothelial growth factor in prostate cancer. Endocrine-related cancer. 2015; 22(3):R107-123.

61. Sharma NL, Massie CE, Ramos-Montoya A, Zecchini V, Scott HE, Lamb AD, MacArthur S, Stark R, Warren AY, 
Mills IG and Neal DE. The androgen receptor induces a distinct transcriptional program in castration-resistant prostate cancer in man. Cancer cell. 2013; 23(1):35-47.

62. Robinson D, Van Allen EM, Wu YM, Schultz N, Lonigro RJ, Mosquera JM, Montgomery B, Taplin ME, Pritchard CC, Attard G, Beltran H, Abida W, Bradley RK, Vinson J, Cao X, Vats P, et al. Integrative clinical genomics of advanced prostate cancer. Cell. 2015; 161(5):1215-1228.

63. Culig Z. Androgen Receptor Coactivators in Regulation of Growth and Differentiation in Prostate Cancer. Journal of cellular physiology. 2015.

64. Brooke GN, Parker MG and Bevan CL. Mechanisms of androgen receptor activation in advanced prostate cancer: differential co-activator recruitment and gene expression. Oncogene. 2008; 27(21):2941-2950.

65. Bevan CL, Hoare S, Claessens F, Heery DM and Parker MG. The AF1 and AF2 domains of the androgen receptor interact with distinct regions of SRC1. Molecular and cellular biology. 1999; 19(12):8383-8392.

66. Comuzzi B, Nemes C, Schmidt S, Jasarevic Z, Lodde M, Pycha A, Bartsch G, Offner F, Culig Z and Hobisch A. The androgen receptor co-activator $\mathrm{CBP}$ is up-regulated following androgen withdrawal and is highly expressed in advanced prostate cancer. The Journal of pathology. 2004; 204(2):159-166.

67. Heemers HV, Sebo TJ, Debes JD, Regan KM, Raclaw KA, Murphy LM, Hobisch A, Culig Z and Tindall DJ. Androgen deprivation increases p300 expression in prostate cancer cells. Cancer research. 2007; 67(7):3422-3430.

68. Powell SM, Christiaens V, Voulgaraki D, Waxman J, Claessens F and Bevan CL. Mechanisms of androgen receptor signalling via steroid receptor coactivator-1 in prostate. Endocrine-related cancer. 2004; 11(1):117-130.

69. Zhong J, Ding L, Bohrer LR, Pan Y, Liu P, Zhang J, Sebo TJ, Karnes RJ, Tindall DJ, van Deursen J and Huang H. p300 acetyltransferase regulates androgen receptor degradation and PTEN-deficient prostate tumorigenesis. Cancer research. 2014; 74(6):1870-1880.

70. Liu C, Wang C, Wang K, Liu L, Shen Q, Yan K, Sun X, Chen J, Liu J, Ren H, Liu H, Xu Z, Hu S, Xu D and Fan Y. SMYD3 as an oncogenic driver in prostate cancer by stimulation of androgen receptor transcription. Journal of the National Cancer Institute. 2013; 105(22):1719-1728.

71. Lee DY, Northrop JP, Kuo MH and Stallcup MR. Histone H3 lysine 9 methyltransferase G9a is a transcriptional coactivator for nuclear receptors. The Journal of biological chemistry. 2006; 281(13):8476-8485.

72. Shin S and Janknecht R. Activation of androgen receptor by histone demethylases JMJD2A and JMJD2D. Biochemical and biophysical research communications. 2007; 359(3):742-746.

73. Jin F, Claessens F and Fondell JD. Regulation of androgen receptor-dependent transcription by coactivator MED1 is mediated through a newly discovered noncanonical binding motif. The Journal of biological chemistry. 2012; 287(2):858-870.

74. Qin J, Lee HJ, Wu SP, Lin SC, Lanz RB, Creighton CJ, DeMayo FJ, Tsai SY and Tsai MJ. Androgen deprivation-induced NCoA2 promotes metastatic and castration-resistant prostate cancer. The Journal of clinical investigation. 2014; 124(11):5013-5026.

75. Ianculescu I, Wu DY, Siegmund KD and Stallcup MR. Selective roles for cAMP response element-binding protein binding protein and p300 protein as coregulators for androgen-regulated gene expression in advanced prostate cancer cells. The Journal of biological chemistry. 2012; 287(6):4000-4013.

76. Bjorkman M, Ostling P, Harma V, Virtanen J, Mpindi JP, Rantala J, Mirtti T, Vesterinen T, Lundin M, Sankila A, Rannikko A, Kaivanto E, Kohonen P, Kallioniemi O and Nees M. Systematic knockdown of epigenetic enzymes identifies a novel histone demethylase PHF8 overexpressed in prostate cancer with an impact on cell proliferation, migration and invasion. Oncogene. 2012; 31(29):34443456.

77. Agoulnik IU, Vaid A, Nakka M, Alvarado M, Bingman WE, 3rd, Erdem H, Frolov A, Smith CL, Ayala GE, Ittmann MM and Weigel NL. Androgens modulate expression of transcription intermediary factor 2 , an androgen receptor coactivator whose expression level correlates with early biochemical recurrence in prostate cancer. Cancer research. 2006; 66(21):10594-10602.

78. Dasgupta S, Putluri N, Long W, Zhang B, Wang J, Kaushik AK, Arnold JM, Bhowmik SK, Stashi E, Brennan CA, Rajapakshe K, Coarfa C, Mitsiades N, Ittmann MM, Chinnaiyan AM, Sreekumar A, et al. Coactivator SRC2-dependent metabolic reprogramming mediates prostate cancer survival and metastasis. The Journal of clinical investigation. 2015; 125(3):1174-1188.

79. Wagner KW, Alam H, Dhar SS, Giri U, Li N, Wei Y, Giri D, Cascone T, Kim JH, Ye Y, Multani AS, Chan CH, Erez B, Saigal B, Chung J, Lin HK, et al. KDM2A promotes lung tumorigenesis by epigenetically enhancing ERK1/2 signaling. The Journal of clinical investigation. 2013; 123(12):5231-5246.

80. Blackledge NP, Zhou JC, Tolstorukov MY, Farcas AM, Park PJ and Klose RJ. CpG islands recruit a histone H3 lysine 36 demethylase. Molecular cell. 2010; 38(2):179190.

81. Van Rechem C, Black JC, Greninger P, Zhao Y, Donado C, Burrowes PD, Ladd B, Christiani DC, Benes CH and Whetstine JR. A coding single-nucleotide polymorphism in lysine demethylase KDM4A associates with increased sensitivity to mTOR inhibitors. Cancer discovery. 2015; 5(3):245-254.

82. Casati L, Sendra R, Poletti A, Negri-Cesi P and Celotti F. Androgen receptor activation by polychlorinated biphenyls: epigenetic effects mediated by the histone demethylase Jarid1b. Epigenetics : official journal of the 
DNA Methylation Society. 2013; 8(10):1061-1068.

83. Kristensen LH, Nielsen AL, Helgstrand C, Lees M, Cloos P, Kastrup JS, Helin K, Olsen L and Gajhede M. Studies of H3K4me3 demethylation by KDM5B/Jarid1B/PLU1 reveals strong substrate recognition in vitro and identifies 2,4-pyridine-dicarboxylic acid as an in vitro and in cell inhibitor. The FEBS journal. 2012; 279(11):1905-1914.

84. Taylor BS, Schultz N, Hieronymus H, Gopalan A, Xiao Y, Carver BS, Arora VK, Kaushik P, Cerami E, Reva B, Antipin Y, Mitsiades N, Landers T, Dolgalev I, Major JE, Wilson $\mathrm{M}$, et al. Integrative genomic profiling of human prostate cancer. Cancer cell. 2010; 18(1):11-22.

85. Yamamoto S, Wu Z, Russnes HG, Takagi S, Peluffo G, Vaske C, Zhao X, Moen Vollan HK, Maruyama R, Ekram MB, Sun H, Kim JH, Carver K, Zucca M, Feng J, Almendro $\mathrm{V}$, et al. JARID1B is a luminal lineage-driving oncogene in breast cancer. Cancer cell. 2014; 25(6):762-777.

86. Huang C, Xiang Y, Wang Y, Li X, Xu L, Zhu Z, Zhang T, Zhu Q, Zhang K, Jing N and Chen CD. Dual-specificity histone demethylase KIAA1718 (KDM7A) regulates neural differentiation through FGF4. Cell research. 2010; 20(2):154-165.

87. Yokoyama A, Okuno Y, Chikanishi T, Hashiba W, Sekine H, Fujiki R and Kato S. KIAA1718 is a histone demethylase that erases repressive histone methyl marks. Genes to cells : devoted to molecular \& cellular mechanisms. 2010; 15(8):867-873.

88. Arteaga MF, Mikesch JH, Qiu J, Christensen J, Helin K, Kogan SC, Dong S and So CW. The histone demethylase PHF8 governs retinoic acid response in acute promyelocytic leukemia. Cancer cell. 2013; 23(3):376-389.

89. Osawa T, Muramatsu M, Wang F, Tsuchida R, Kodama $\mathrm{T}$, Minami $\mathrm{T}$ and Shibuya M. Increased expression of histone demethylase JHDM1D under nutrient starvation suppresses tumor growth via down-regulating angiogenesis. Proceedings of the National Academy of Sciences of the United States of America. 2011; 108(51):20725-20729.

90. Upadhyay AK, Rotili D, Han JW, Hu R, Chang Y, Labella D, Zhang X, Yoon YS, Mai A and Cheng X. An analog of BIX-01294 selectively inhibits a family of histone H3 lysine 9 Jumonji demethylases. Journal of molecular biology. 2012; 416(3):319-327.

91. Mimasu S, Umezawa N, Sato S, Higuchi T, Umehara $\mathrm{T}$ and Yokoyama S. Structurally designed trans-2phenylcyclopropylamine derivatives potently inhibit histone demethylase LSD1/KDM1. Biochemistry. 2010; 49(30):6494-6503.

92. Betel D, Wilson M, Gabow A, Marks DS and Sander C. The microRNA.org resource: targets and expression. Nucleic acids research. 2008; 36(Database issue):D149-153.

93. Goldman M, Craft B, Swatloski T, Cline M, Morozova O, Diekhans M, Haussler D and Zhu J. The UCSC Cancer Genomics Browser: update 2015. Nucleic acids research. 2015; 43(Database issue):D812-817.
94. Mongan NP, Martin KM and Gudas LJ. The Putative Human Stem Cell Marker, Rex-1 (Zfp42): Structural Classification And Expression In Normal Human Epithelial And Carcinoma Cell Cultures. Molecular carcinogenesis. 2006; 45(12):887-900.

95. Huang J, Sengupta R, Espejo AB, Lee MG, Dorsey JA, Richter M, Opravil S, Shiekhattar R, Bedford MT, Jenuwein $\mathrm{T}$ and Berger SL. p53 is regulated by the lysine demethylase LSD1. Nature. 2007; 449(7158):105-108.

96. Kashyap V and Gudas LJ. Epigenetic regulatory mechanisms distinguish retinoic acid-mediated transcriptional responses in stem cells and fibroblasts. The Journal of biological chemistry. 2010; 285(19):1453414548 .

97. Mongan NP, Jaaskelainen J, Green K, Schwabe JW, Shimura N, Dattani M and Hughes IA. Two de novo mutations in the AR gene cause the complete androgen insensitivity syndrome in a pair of monozygotic twins. The Journal of clinical endocrinology and metabolism. 2002; 87(3):1057-1061. 